\title{
"Circulación de memes en WhatsApp: ambivalencias del humor desde la perspectiva de género"'
}

\author{
"WhatsApp Memes: Humor's ambivalences from a gender \\ perspective"
}

\author{
Esmeralda Ballesteros Doncel \\ Universidad Complutense de Madrid \\ eballest@ucm.es (ESPAÑA)
}

Recibido: 26.04 .2016

Aceptado: 29.08.2016

\section{RESUMEN}

La aplicación WhatsApp se ha convertido en todo un fenómeno social. Todo el mundo se relaciona por WhatsApp, enviando mensajes multimedia y, en ocasiones, memes. Piezas verbo-visuales surgidas en la cultura digital y que pretenden la risa de sus receptores. Este artículo explora un repertorio de memes capturados durante seis meses en un grupo de WhatsApp, formado por mujeres asalariadas con edades comprendidas entre 50 y 55 años. El análisis comienza con una caracterización de la gramática del meme tipo para, a continuación, examinar las temáticas e interpretar el sentido de los contenidos humorísticos distribuidos. Los resultados sugieren que el humor es algo más que divertimento y que la risa también está mediada por la estructura social, desprendiendo destellos de una cultura que mantiene sesgos de género, orientados indistintamente a mujeres y hombres.

\section{PALABRAS ClAVE}

Cultura digital, Memes, WhatsApp, Humor y género, Estudios culturales.

${ }^{1}$ Me gustaría expresar mi agradecimiento a Araceli Serrano y Elena Casado por su lectura cómplice del primer borrador de este artículo; también a las personas que lo evaluaron, sugiriéndome sutiles reflexiones. 


\begin{abstract}
WhatsApp has become a social phenomenon. Everyone talks on WhatsApp! Users sending multimedia messages and sometimes memes: a visual-verbal joke emerged in digital culture to induce humorous responses in its receivers. This article analyzes a selection of memes captured for six months in a group of employed women aged between 50 and 55 years. The analysis begins with a characterization of prototypical meme. Then examines the topics and interprets the meaning of content distributed humorous. The results suggest that humor is more than laughter and humor is mediated by the social structure. Memes reflects the androcentric culture but now women and men are mocked equally.
\end{abstract}

\title{
KEY WORDS
}

Digital Culture, Memes, WhatsApp, Humor and Gender, Cultural Studies.

\section{INTRODUCCIÓN}

La aparición de WhatsApp en 2009, como una nueva aplicación de mensajería instantánea multimedia, ha provocado pequeñas revoluciones. Desbancó el reinado de los 'SMS' y ha entrado a formar parte, al menos en España, de nuestras relaciones sociales cotidianas. Las estadísticas señalan que este recurso conversacional es de uso frecuente para millones de personas. $\mathrm{Su}$ preferencia guarda relación con que se ofrece como aplicación gratuita, de manejo sencillo pero integradora y versátil. Con una sola app, se puede recibir y distribuir texto, audio, imágenes y audiovisual, permitiendo una amplia flexibilidad en la comunicación interpersonal -bis a bis, grupos, eventos, listas de difusión, etc-, donde, además, las personas usuarias hacen y deshacen entran y salen, silencian o bloquean-, diseñan relaciones 'a la carta' -con quién, cuánto y cómo-. Su probada expansión permite reconocerlo como fenómeno, tanto para nativos como inmigrados a las nuevas tecnologías, y esta también es una novedad sociológica ${ }^{2}$. Esta preeminencia ha favorecido su selección como objeto de estudio en distintas áreas de conocimiento -educación, relaciones de interpersonales, adiciones tecnológicas, etc.-, aunque poco se ha analizado su potencialidad como espacio para la distribución de humor.

Este artículo explora un repertorio de memes online, distribuidos en un grupo definido de WhatsApp, desbrozando simultáneamente algunas de sus

${ }^{2}$ Si bien la distinción entre los denominados 'nativos' versus ‘inmigrados' a las NTIC parece difusa, se utiliza aquí para enfatizar la transversalidad de la aplicación que, entre otras cuestiones, han propiciado comunicaciones abiertas entre personas de características socio-demográficas muy distintas. Por ejemplo, los variados grupos de familia que relacionan virtualmente parientes de distintas generaciones etarias, que pueden no haberse visto en años y que WhatsApp re-conecta con regularidad. 
características como producto cultural y como práctica social. Si bien las investigaciones sobre cultura digital son cada día más numerosas (Lasén y Casado, 2014), la atención prestada al análisis de memes ha sido escasa, a pesar de que estos se han convertido en un código de comunicación continuo, cotidiano y universal (Shifman, 2013). Los memes, en su vertiente humorística, se perciben como 'píldoras de bienestar', en tanto son breves estímulos cómicos que pretenden provocar la risa o, al menos, una sonrisa. Acciones ambas placenteras y sanadoras (Urroz, 2005: 11).

En la primera parte de esta reflexión, se contextualiza la expansión del fenómeno WhatsApp. A continuación, se describen las gramáticas del 'meme' asociadas a su contenido humorístico y, por último, se presentan los resultados de una observación virtual, practicada entre los meses de abril y octubre de 2014, en un grupo formado por 29 mujeres de entre 50 y 55 años, empleadas en la misma empresa y residentes en diferentes localidades de la geografía española ${ }^{3}$. Durante seis meses se capturaron los memes compartidos en el grupo. A partir de su análisis se ha pretendido caracterizar el humor compartido, teniendo en cuenta las características socio-demográficas del grupo. Resultaba interesante testar hasta qué punto las habilidades digitales adquiridas son una oportunidad para proponer y diversificar contenidos -humor creativo- o esta aplicación es un nicho virtual para la re-producción de tendencias cómicas. En concreto se planteó examinar si, el humor distribuido en formato meme, en un grupo de mujeres económicamente independientes y maduras, permitía la circulación de bromas convencionales de naturaleza sexista ${ }^{4}$.

\section{BREVE CONTEXTUALIZACIÓN DEL FENÓMENO WHATSAPP}

WhatsApp se ha convertido, en poco tiempo, en todo un 'boom'. Lanzada en 2009, como una aplicación de mensajería instantánea multimedia por dos antiguos directivos de Yahoo, se ha incorporado a nuestra vida cotidiana. La información estadística disponible indica que es, con mucha diferencia, la principal aplicación utilizada en España. El Barómetro del CIS, relativo a septiembre de 2014, señalaba que el 96,4 por ciento de los usuarios de mensajería multimedia eligen WhatsApp, siendo la intensidad de conectividad frecuente o muy frecuente 5 . Por su parte, los resultados de la encuesta AIMC ( $17^{\mathrm{a}}$ edición) reafirman el mismo liderazgo. A nivel mundial, según el portal

3 En el transcurso de otra investigación, en la que se abordaba el estudio de las condiciones laborales de la ocupación de maquinistas ferroviarios, se tuvo la oportunidad de realizar entrevistas en profundidad y participar de diversas reuniones de este colectivo. Estas profesionales me incluyeron en su grupo de WhatsApp en el transcurso del V Encuentro de Mujeres de Tracción, celebrado en Asturias los días 5-6 de abril de 2014.

4 Se emplea el término sexista para hacer referencia a las diferencias biológicas hombre/mujer que, partiendo de la diferencial genitalidad, abogan por asignar roles sociales diferenciados entre los sexos y que constituyen uno de los argumentos legitimadores de las desigualdades de género.

5 Estudio CIS núm. 3038 (2/09/2014). Universo: Población española / ambos sexos / 18 y más años. Tamaño de la muestra 2.444 -preguntas 19,27 y 30-. 
Statista, WhatsApp ha alcanzado ya los 1.000 millones de usuarios y, aunque su cuota de expansión es muy desigual entre países ${ }^{6}$, es innegable su consolidación como un codiciado objeto de negocio ${ }^{7}$.

WhatsApp ha modificado nuestra forma de comunicación mediada por las tecnologías, diversificando de manera creativa la composición de textos, enriquecidos con símbolos e iconos visuales que transforman la gramática conversacional (Wesch, 2009). Sin embargo, poco o nada sabemos sobre la diversidad de prácticas y usos que pueden desarrollarse en WhatsApp, por ejemplo, si ha posibilitado restringir ostensiblemente llamadas y, a la vez, mantener contacto con más usuarios; si se utiliza más de forma privada (bis a bis) o pública (grupos); de las tendencias según códigos de comunicación (imágenes, memes, audios, videos, enlaces, etc.); de las posibles formas de control (revisar los tiempos de conexión de los contactos, silenciar grupos, bloquear contactos, etc.); de la violencia simbólica que implica la no-pertenencia o el abandono de un grupo (riesgo de aislamiento); de las prácticas colaborativas (completar tareas y actividades docentes/laborales), o de los potenciales de evasión que ofrece cuando se está en un espacio que aburre ${ }^{8}$; Sin olvidar los procesos de saturación que genera o, más recientemente de prácticas ilícitas 9 .

Esta omnipresencia ha generado resonancias sociales que se mueven en sentidos contrarios, generando tecno-filias y tecno-fobias a la aplicación, además de caricaturas profesionales y amateurs sobre cómo esta app está transformando nuestra rutina diaria. La hegemonía de WhatsApp encuentra eco en diferentes acciones y producciones. Un ejemplo de su instrumentalización en la capacidad de alcanzar audiencias, se tiene en el fenómeno fan de los 'ministéricos' ${ }^{10}$. El lenguaje fílmico tampoco ha obviado su emergencia y ha ficcionado el fenómeno con diversos cortos cinematográficos virales como Doble Chek (2012), Yo tb tq (2013) o, Dis-Connect (2013) ${ }^{11}$. Incluso, desde la música disco se narran las

${ }^{6}$ Los cinco territorios de mayor difusión son Sudáfrica, Malasia, Argentina, Singapur y Hong Kong (más $70 \%$ ); supera el 50 por ciento en Brasil, Alemania, Holanda e Italia y su uso es minoritario en Francia y Estados Unidos (Statista, 2016: 28-29).

7 En octubre de 2014, Facebook adquirió la aplicación por un multimillonario valor según informó la agencia europapress - http://www.europapress.es/internacional/noticia-facebook-comprawhatsapp-cerca-22000-millones-dolares-20141007004852.html -

${ }^{8}$ El uso de WhatsApp en las aulas universitarias es una práctica habitual que se advierte como una desconexión ¿lúdica? cuando la clase no interesa

${ }^{9}$ El caso del colegio público Tomé y Orgaz (Casarrubuelos -Madrid) en mayo de 2015 es sólo un ejemplo de los difusos límites entre lo privado y lo público, lo lícito y lo ilícito que pueden producirse en grupos de Whatsapp.

${ }^{10} \mathrm{El}$ 'community manager' de la serie televisiva El Ministerio del Tiempo, Agustín Alonso, desarrolló una estrategia digital de promoción que además de Twitter, Facebook e Instagram, contempló la novedad de crear un grupo de Whatsapp (http://www.rtve.es/television/20160127/ grupo-whatsapp-ministerio-del-tiempo-segunda-temporada/1291164.shtml).

${ }^{11}$ Existen otras creaciones audio-visuales, de producción no profesional, que también representan cómicamente el fenómeno de 'adición sin sustancia' que ha inoculado esta aplicación: El hombre sin Whatsapp (2013); iDiots, la parodia a los usuarios del iPhone (2013) o el video clip Sin WhatsApp, sin WhatsApp (2013). 
peripecias ordinarias de los usos que proporciona ${ }^{12}$. Sin ignorar las parodias realizadas por profesionales de humor en programas televisivos de gran audiencia $^{13}$. Estas prácticas no sólo confirman la importancia socio-cultural de la app, sino que también sugieren como señaló Becker (2007) que, para hablar de la sociedad, la sociología no basta.

En sentido contrario se pueden citar los, cada vez más numerosos, artículos de prensa que reprueban la saturación y el hastío que puede llegar a provocar en la gestión del tiempo la 'obligada' conexión a los dispositivos móviles, que determinan incesantes interacciones cotidianas.

En síntesis, WhatsApp y los usos sociales que de esta app se hacen parecen estar transformado nuestras rutinas de comunicación mediadas por la tecnología. Es por ello, y a tenor de las resonancias señaladas, que parece justificada su selección como objeto de estudio.

\section{MEMES, NUEVO FORMATO DIGITAL DEL HUMOR}

El término meme se emplea, por lo general, para referirse a una composición verbo-visual o audio-visual, de naturaleza digital que se transmite por la red, siendo susceptible de evolucionar, a medida que viaja virtualmente. Según el diccionario Oxford, deriva de la palabra griega mimēma -aquello que se imita- y fue utilizada por primera vez por el biólogo Richard Dawkins en el libro El gen egoísta (1976), para definir esas frases, conductas o melodías populares que, en cada cultura, se difunden por imitación de una generación a la siguiente. En la actualidad los memes, a diferencia de las unidades culturales estables y perdurables a las que se refería Dawkins, son contenidos de naturaleza diversa -política, sexo, identidades, etc.- que adquieren una rápida popularidad en la web, siendo susceptibles de evolucionar, a medida que son comentados o recontextualizados (Shifman, 2012: 190).

A diferencia de otras publicaciones que estudian memes distribuidos por internet de carácter dinámico (Shifman, 2012; Wiggins y Bowers, 2015), en este artículo los memes objeto de estudio se refieren a imágenes verbo-visuales de naturaleza estática. Si bien las temáticas que contienen son múltiples, en esta reflexión se hará referencia a las piezas con orientación humorística ${ }^{14}$.

La característica principal de los memes, al igual que el chiste, es la brevedad. Una de sus pretensiones consistiría en relativizar y poner distancia, desde el humor, a las tensiones, malestares y conflictos de la vida cotidiana (Vigara, 2013: 8-11; Izquierdo y Barbeta, 2013: 1101).

12 Videoclip de David Cesar Que guasa tiene el whatsapp (2013).

${ }^{13}$ Alex Clavero en Sopa de Gansos (El glorioso día en el que tu madre se baja el 'WhatsApp'; Si no tienes 'WhatsApp', no tienes vida); Chema Ruiz en Sopa de Gansos ('Odio los grupos de whatsapp, son las sectas del siglo XXI); Quequé en el Club de la Comedia (Le pido al WhatsApp que saque la 'special edition mother'), David Guapo en el Club de la Comedia (¿Alguien puede acabar con ese invento del demonio?).

${ }_{14}$ Ellie Goulding 
De manera general, su composición combina una imagen -fotografía o dibujo-, sobre la que se inserta un texto, aunque de forma menos frecuente se pueden también encontrar memes exclusivamente textuales o visuales (cuadro 1). La mayoría de los memes utilizan la tipografía 'Impact', en color blanco, con predominio de la mayúscula. Esta tendencia puede explicarse tanto desde su morfología orientada a titular -comprimida y gruesa-, como porque fue uno de los primeros tipos de letra disponibles en el sistema Windows y el software gratuito incorporado -tipo MS Paint-.

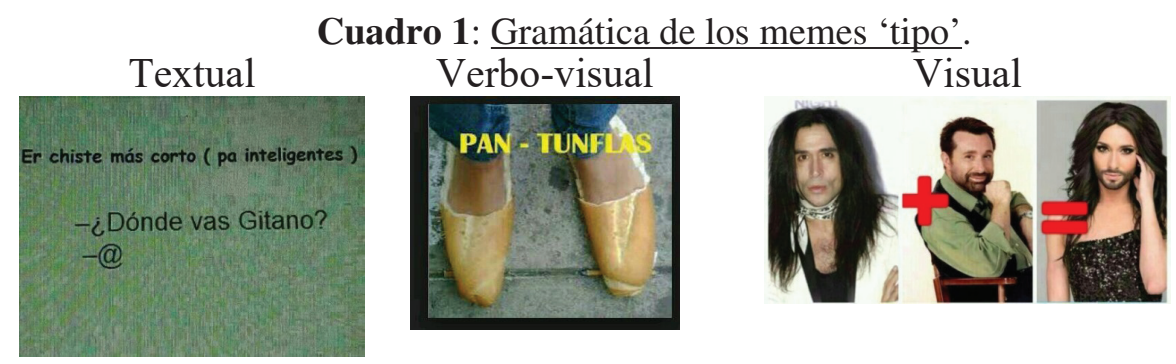

Tras examinar el corpus de datos reunido, se han advertido una serie de características generales. En relación a la imagen, los recursos iconográficos empleados son diversos; Desde referentes estandarizados de humor -expresiones faciales de niños y niñas-; animales comunes -gatos, perros o monos-; famosos de toda índole -políticos, deportistas, actores, etc.-; e incluso personajes de ficción como Mafalda o Homer Simpson, conocidos y compartidos por una amplia base social. No obstante, también un registro fotográfico disruptivo caída, carcajada o desconcierto- puede estimular la producción de un meme. Esta última modalidad prolifera en torno a las resonancias informativas sucesos socio-políticos de actualidad (Dynel, 2016: 662).

Es importante advertir que la gramática de los memes es indisociable de las capacidades digitales de las personas que los crean o re-crean. En un nivel básico se identifican piezas diseñadas desde aplicaciones gratuitas y disponibles on-line. Apps que permiten crear un meme en segundos haciendo uso de un banco de imágenes pre-determinado (generalmente fotografías de famosos), al que se inserta un texto (parte superior, parte inferior o, ambos) ${ }^{15}$. La facilidad y accesibilidad para crear memes estándar implica que una misma referencia icónica se emplee para generar múltiples memes des-territorializados (cuadro 2).

15 Las aplicaciones más usadas son 'Memedroid', 'Diseño de Memes', 'Meme Producer', 'Meme Factory', 'Meme Generator' y 'GATM'. 
Cuadro 2: Diversos memes compartiendo la base de la imagen ${ }^{16}$.
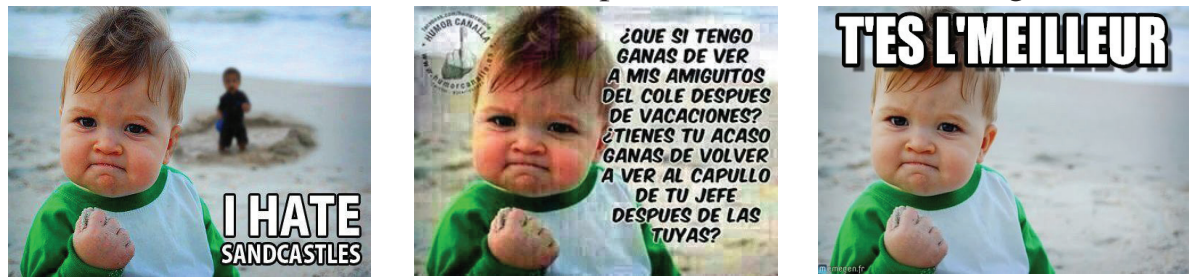

Por otro lado, se pueden identificar composiciones con variable grado de complejidad, basadas en la transformación de imágenes mediante software especializado para obtener piezas ficcionadas pero vinculadas a la actualidad informativa. En este caso, los memes suelen incorporar una identificación de su autoría (cuadro 3).

Las condiciones de posibilidad de los memes, como dispositivo cómico, dependen del ingenio de la pieza, las destrezas tecnológicas de sus creadores y el contexto de recepción, es decir, de una aceptación vinculante.

Cuadro 3: Memes con imágenes manipuladas o ficcionadas.

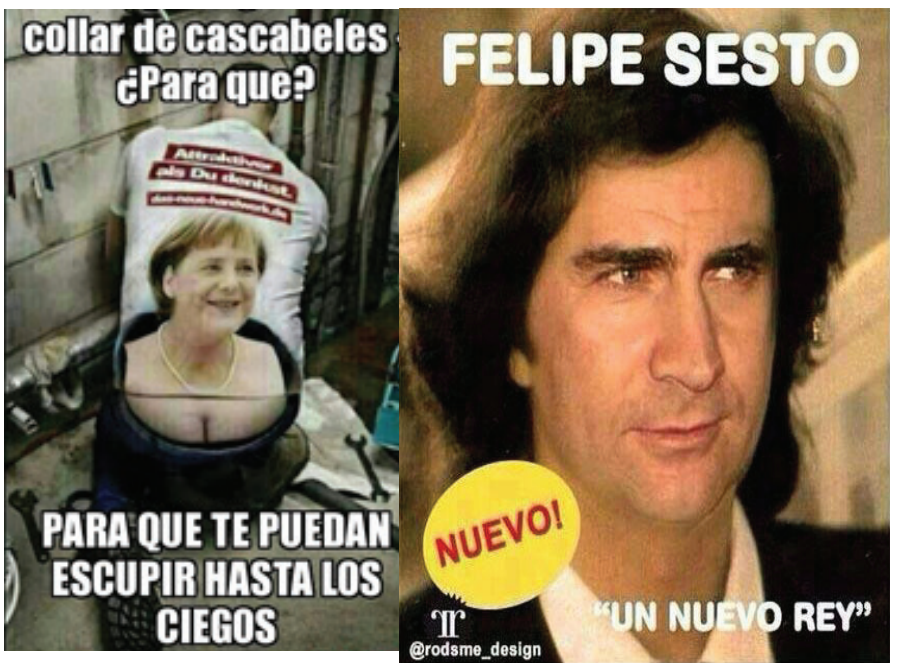

A menudo, se atribuye a este nuevo formato de distribución de humor un potencial inagotable del ingenio creativo, aunque como para el resto de las actividades humanas, una observación sistemática permite advertir redundancias por imitación y/o plagio que implica una duplicación de piezas, con ligeras

${ }^{16}$ De manera marginal, en el proceso de observación se identificaron composiciones de parejas de memes y piezas elaboradas a partir de series de imágenes. 
variaciones en el color o la inversión de roles. Los memes del cuadro 4 son variaciones de una viñeta cómica firmada por la historietista Maitena ${ }^{17}$.

Cuadro 4: Memes con contenido plagiado y re-interpretado.
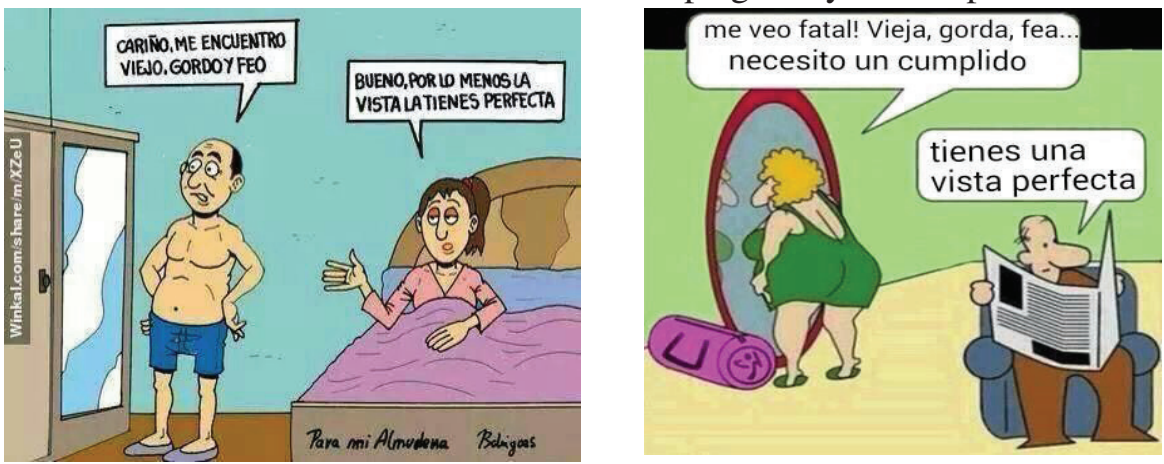

Una pregunta interesante, que fue surgiendo a lo largo de esta reflexión, era plantear si el meme de carácter estático debe considerarse una versión 'tecnologizada' del chiste convencional o, un nuevo producto cultural. A este respecto y atendiendo a los elementos que caracterizan ambas producciones culturales, mi interpretación se inclina por la segunda opción. El chiste se transmite de forma canónica mediante la oralidad y, por tanto, además del contenido, sus efectos dependen tanto de la gestualidad, la entonación y las formas de dicción, pues es un relato situado y, en cierto modo, teatralizado. El meme, por el contrario, carece de sonido y condensa en la combinación de imagen y texto el mensaje cómico. La investigadora Limor Shifman va más allá afirmando que, los memes son algo más que un pasatiempo o diversión siendo, según sus propias palabras, "a (post)modern folklore" (2013: 15).

Otra evidencia de cómo el meme estático, con orientación humorística, se ha convertido en un nuevo pero reconocible código cultural, es su adopción en el medio publicitario como formato de comunicación. En enero de 2016, la empresa de crédito Yomoni lanzó una campaña publicitaria en Francia, diseñada por Jonathan Menet, en la que se empleaban tres memes para disuadir a pequeños ahorradores a obtener una mayor rentabilidad de su dinero. Estos «chistes» de la era digital, según Menet (2016), ofrecen un formato socialmente reconocido, que servía en este caso para burlarse de la política de intereses bancarios o de los discursos tecnócratas de las entidades financieras ${ }^{18}$.

17 Mujeres Alteradas (2006) "La mujer desnuda, mirándose al espejo de la habitación (...) No está feliz con lo que ve y dice al marido: -Me siento horrible, parezco vieja, gorda y fea. Por favor, necesito un elogio tuyo. El marido responde: -De la vista estás perfecta (...) Y, entonces, comenzó la pelea".

18 Se puede leer una breve entrevista a Jonathan Menet y visualizar los memes de la campaña publicitaria en la siguiente dirección URL http://www.jonathan-menet.fr/blog/2016/01/19/yomoniun-acteur-de-lepargne-a-la-mode-du-meme/ 
Se deduce en cambio que, el meme estático de orientación cómica, encuentra semejanzas con la viñeta de humor de la prensa gráfica, un género profesional muy popular, hasta el punto de que muchas veces lo único que interesa del periódico es observar la tira cómica (Segado, 2009: 205). Pero, a diferencia de aquél, ahora el humor gráfico propuesto dejaría de ser un patrimonio exclusivo de aquellos profesionales.

Efectivamente, el acceso a las tecnologías móviles y el acceso a sus múltiples aplicaciones facilitarían 'presuntamente' una democratización en la producción y distribución de ocurrencias satíricas, resonancias informativas, etc. De modo que, cualquiera podría, a priori, diseñar memes. Sin embargo ¿hasta qué punto esta oportunidad se desarrolla entre la base de usuarios de mensajería instantánea multimedia? Muchas de las publicaciones que han analizado la cultura digital, suelen concluir que las nuevas tecnologías han favorecido una cultura participativa (Jenkins, 1992; Islas, 2008; 2014; Shifman, 2012: 198-199). La aparición del término 'prosumidor' implica asumir que cualquier usuario de las nuevas tecnologías puede, simultáneamente, desempeñar un doble rol: productor de contenidos y consumidor (Islas, 2008: 35-36).

Sin negar la evidencia, sería necesario matizar esta afirmación, pues se debería estimar el grado de participación entre personas usuarias (distribuidoras) y personas creadoras de contenidos. Se sugiere un ejemplo. El Movimiento de Liberación Gráfica Madrid (MLGM), formado por artistas independientes, desarrolló una extensa actividad creativa mediante el diseño de retratos, carteles, GIFS, etc. para apoyar la candidatura de Manuela Carmena a la alcaldía de Madrid $^{19}$. Las piezas circularon y se hicieron virales en diversas redes sociales, llegando incluso a adoptarse por algunas personas como 'imagen de perfil', en los días previos a las elecciones. Sin embargo, se puede advertir una participación estética-técnica muy desigual (cuadro 5) que induce a re-pensar la asimilación generalista entre personas usuarias y personas creadoras de contenidos. Convertir en viral una pieza pone en juego, no sólo la intención sino también las destrezas técnicas, dominio que no es general.

19 Para ver las producciones se puede acceder al grupo de Facebook Movimiento de Liberación Gráfica Madrid https://www.facebook.com/MLGM-Movimiento-de-Liberaci\%C3\%B3nGr\%C3\%A1fica-Madrid-663597840432462, fecha de acceso octubre de 2015. 


\section{Cuadro 5: Piezas difundidas por Movimiento de Liberación Gráfica} Madrid.
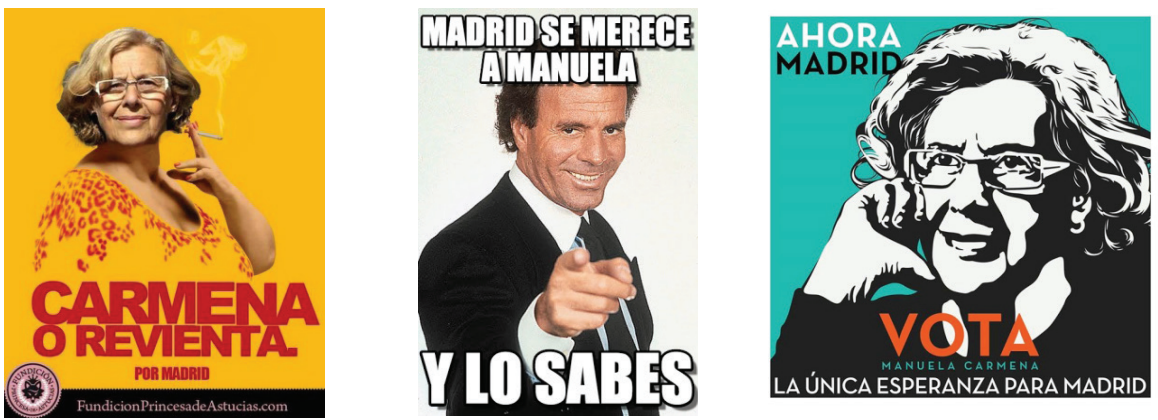

En ausencia de otras evidencias empíricas, la hipótesis más plausible es pensar que la práctica de crear contenidos se polariza en una minoría de sujetos; Una idea enunciada hace más de veinte años por Everett Rogers (1995) en su conocida 'curva de difusión de la innovación'. Las personas que adoptan las propuestas y nuevas competencias que ofrecen las nuevas tecnologías de las comunicación -early adopters-, son una magnitud marginal entre el conjunto de cibernautas. No obstante, esta minoría puede tener una enorme capacidad para promocionar ideas, relativizar malestares, emitir juicios críticos o difundir sátiras, captando la atención de una amplia base social. A ello se refería también Clay Shirky (2005), cuando describe la participación en plataformas colaborativas; Utilizando un ejemplo sobre fotos de Iraq en Flickr, Shirky demuestra que las personas que realizan una contribución prolífica son estadísticamente un porcentaje muy pequeño. Por el contrario, el 80 por ciento del banco de datos de imágenes fue creado por pequeñas colaboraciones de cientos de usuarios -ley de distribución de potencia- ${ }^{20}$. Dicho de otra manera, el hecho de que las potencialidades de participación de las aplicaciones móviles sean enormes, no implica que sean utilizadas de manera similar por el conjunto de las personas usuarias. Esta cuestión vendría a matizar el alcance de las afirmaciones sobre cultura digital colaborativa y sugiere examinar con meticulosidad las piezas verbo-visuales producidas por una minoría y compartidas por la mayoría. Y aunque, ciertamente, una buena parte de estos memes se desvanecen con la misma rapidez con la que emergen -humor líquidoestán presentes de manera continua en nuestra cotidianeidad, por lo que se convierten en un objeto de investigación irrenunciable.

Los memes compartidos en WhatsApp estarían enriqueciendo y aumentando nuestra práctica ordinaria con el humor, pues están presentes en el uso

${ }^{20}$ Clay Shirky (2005): "Institutions vs. Collaboration", TEDGlobal disponible en https:// www.ted.com/talks/clay_shirky_on_institutions_versus_collaboration, fecha de acceso marzo de 2016. 
cotidiano de las tecnologías móviles y se advierten como una acción social de nuestra 'agencia compartida' (Lasén, 2012). Nadie hubiera imaginado que una aplicación de mensajería diese lugar a una práctica socio-cultural lúdica y masiva, como está resultando la circulación de memes, una experiencia distinta a la interacción comunicativa del mensaje textual o/y oral. De modo que, WhatsApp se presenta como un 'espacio intermedio' en la configuración de imaginarios, que debe ser incorporado a las nuevas líneas de la investigación social, tan devota de la perspectiva mediocéntrica que prioriza el análisis de la prensa, el cine o la televisión (Abril, 2010: 23).

\section{ANÁLISIS DE LOS MEMES DISTRIBUIDOS EN UN GRUPO DE WHATSAPP}

En el transcurso del $V$ Encuentro de Mujeres de Tracción (5-6 de abril de 2014) fui incorporada a un grupo de WhatsApp formado por 29 mujeres maquinistas de tren-. El grupo posee algunas características sociológicamente interesantes: constituyen una 'minoría extrema' en una ocupación de dominación masculina (78 mujeres de un total de 5.349 agentes de conducción); sus trayectorias laborales son prolongadas y estables (RENFE y ADIF), perciben una copiosa retribución salarial, residen en diversas localidades de la península, aunque quizá lo más sugerente sea el que estas trabajadoras empezaron a 'hacer club' en 2010 (tres décadas después de integrarse en RENFE). Desde entonces mantienen diversas formas de interacción on-line (Facebook y WhatsApp) y off-line (comidas, encuentros, etc.) que las vincula y, por supuesto, afirma sus identidades ${ }^{21}$.

La característica etaria del sujeto de observación, 50-55 años-, resultó un atractivo elemento, en tanto que la mayoría de las investigaciones sociales sobre nuevas tecnologías de la información y la comunicación adopta una preferencia recurrente por los 'jóvenes' como principal categoría de análisis (Gordo y Megías, 2006; Blais et Al., 2008; Romero y Perlado, 2015)22. Si bien es cierto que esta contribución está basada en un estudio de caso, lo que implica

21 No es objeto de este artículo explorar las potencialidades de los grupos de WP como catalizador de identidades. Sin embargo, resulta interesante enunciar algunas hipótesis. En el caso que nos ocupa y teniendo en cuenta que las mujeres que se incorporan a ocupaciones de dominación masculina han sido objeto de diversas formas de discriminación y rechazo, por parte de sus pares varones (Martin y Barnard, 2013; Ballesteros, 2016), la interacción de estas personas en espacios virtuales produciría interesantes beneficios: a) La existencia del grupo refuerza la frecuencia de contacto entre personas geográficamente dispersas -mecanismo vinculante-; b) Favorece conversaciones regulares entre sus miembros, reafirmando la identidad del grupo y, no sólo a través de conversaciones convencionales, sino mediante dispositivos humorísticos -memes compartidos-. Así lo sugiere la investigación empírica de Blais, et.Al (2008), con jóvenes adolescentes, que concluye que los grupos interconectados, mediante redes, aumentan la confianza y la comunicación entre sus miembros.

22 En este punto resulta interesante destacar el proyecto de Beneito (2015) sobre la apropiación de competencias de la 'gente mayor' en nuevas tecnologías y redes sociales. 
relativizar su alcance, el repertorio de documentos compilado ha brindado la oportunidad de 'regolisnear' sobre distribución del humor digital en una community online (Sádaba, 2015: 461), es decir, de transitar por un contexto privilegiado de análisis, a medio camino entre lo público y lo privado.

Entre los meses de abril y octubre de 2014 se capturaron 491 memes. Sobre este acervo de información, se planteó analizar 'lo que es compartido' (topics) para explorar la hipótesis enunciada al principio: hasta qué punto el humor distribuido en formato meme, en un grupo de mujeres económicamente independientes y maduras, resultaba impregnado de la omnipresente cultura androcéntrica.

Partiendo, de la discutible idea, de que la producción de memes es una práctica minoritaria entre el conjunto de usuarios de nuevas tecnologías. El único rastro de afección a los memes es la distribución. La acción 'volver a enviar' se considera un indicio de reconocimiento de lo gracioso y al re-enviarlo se tendría en cuenta quién o quiénes lo consideran igualmente cómico, pues el humor como cualquier acción social, no es un ejercicio indiferenciado, sino que estaría atravesado por la estructura social (Berger, 1997: 11) ${ }^{23}$. De este modo, se pre-supone que los contenidos de distribución, en este caso de memes, reflejarían formas de identificación de las personas que conforma un grupo de WhatsApp ${ }^{24}$. En este sentido, se esperaba que el humor distribuido entre el sujeto de observación no reflejará el talante sexista tantas veces advertido en el humor sobre mujeres (Martín, 2005: 89).

La categorización de datos no es un ejercicio exento de controversia y, sin embargo, es una acción de irrenunciable pragmatismo. En la tabla 1 se muestra la clasificación del conjunto de memes compilado, advirtiendo que algunas piezas podrían haber sido vinculadas a más de una categoría, pues el contenido mezcla diferentes temas. Pese a la diversidad, se advierte una preeminencia de memes de humor generalista, asociados a 'chistes', en sentido convencional, y 'resonancias informativas" ${ }^{25}$.

${ }^{23}$ La polémica en torno al concejal del Ayuntamiento de Madrid, Guillermo Zapata (junio de 2015), puede ser tomado como un ejemplo ilustrativo de cómo un chiste distribuido en twitter puede desencadenar un debate político y ser instrumentalizado como campaña de descalificación de un gobierno municipal.

${ }^{24}$ Soy consciente de la fragilidad de la hipótesis planteada, en tanto que los memes, por sí mismos, no pueden adoptarse como evidencias de posicionamiento ideológico. Hubiera sido necesario, desarrollar alguna técnica de análisis del discurso, bien realizando entrevistas en profundidad, bien grupos de discusión, para indagar cómo se ubicarían nuestros sujetos de observación en relación a los memes compilados.

${ }_{25}$ Probablemente, los memes producidos a tenor de noticias de la actualidad política y/o la agenda informativa son los más numerosos. Cualquier frase, expresión, gesto o prenda de vestir puede dar lugar a una tormenta de resonancias cómicas, en formato verbal y verbo-visual. Véanse, a este respecto, las múltiples reacciones que provocaron 'los meñiques de la alcaldesa de Jerez, Mamen Sánchez, en su toma de posesión (junio de 2015). 
Tabla 1: Memes capturados y clasificados en categorías

\begin{tabular}{rlrr}
\hline Categorías de clasificación & \multicolumn{2}{c}{$\begin{array}{c}\text { Frecuencia } \\
\text { absoluta }\end{array}$} & Porcentaje \\
\hline 1. & Resonancias informativas & 103 & 21,0 \\
2. & Chistes & 98 & 20,0 \\
3. & Tiempo y descanso & 74 & 15,1 \\
4. & Inteligencia emocional y auto-ayuda & 68 & 13,8 \\
5. & Mujeres y Hombres -relaciones y asimetrías- & 56 & 11,4 \\
6. & Expresando el deseo & 33 & 6,7 \\
7. & Cumpleaños - Aniversarios & 27 & 5,5 \\
8. & La ambivalente relación con el cuerpo & 20 & 4,1 \\
9. & Conciencia feminista & 6 & 1,2 \\
10. Whatsapp & 6 & 1,2 \\
TOTAL & $\mathbf{4 9 1}$ & $\mathbf{1 0 0 , 0}$ \\
\hline
\end{tabular}

La tercera categoría, con mayor número de memes, se ha denominado 'Tiempo y descanso'. Una temática muy vinculada a una característica identitaria del grupo, pues la conducción ferroviaria organiza la jornada en turnos rotativos, lo que implica un baile de horarios que se traduce en una acusada percepción de fatiga.

Una línea disonante, dentro del conjunto de la orientación humorística de los memes, es la rúbrica nombrada 'Inteligencia emocional y auto-ayuda' y que contiene recomendaciones, deseos y orientaciones para mejorar la vida personal, enfatizando las potencialidades individuales de la felicidad. Este es un fenómeno ampliamente mercantilizado por el negocio editorial y al que habría que sumar los memes vinculados a felicitaciones de cumpleaños y aniversarios -Día de la Madre, Día del Libro, 8 de Marzo, etc.-. 
Pese al volumen y diversidad identificados en el contenido de unidades de análisis, la hipótesis planteada condicionó la selección intencionada de tres categorías: 1) 'Mujeres y Hombres: relaciones y asimetrías', 2) 'Expresando el deseo' y 3) 'La ambivalente relación con el cuerpo'.

\subsection{Mujeres y hombres -relaciones y asimetrías-}

El humor tiene diversas funciones (Berger, 1997: 67-74) aunque sin duda puede mostrar, mediante la distancia de lo cómico, malestares estructurales. Tal sería el caso sobre los conflictos cotidianos de las pajeras heterosexuales, con una convivencia prolongada. Sus desencuentros han sido representados en diferentes formatos comunicativos -novela, cine o teatro-. Por citar algunos ejemplos, la obra de teatro El Cavernícola-Defending the Caveman-, escrita por Rob Becker (1991), se ha convertido en líder de permanencia en cartel de toda la historia de Broadway, habiéndose adaptado y representado en más de 45 países y traducida, hasta el momento, a 18 idiomas ${ }^{26}$. Un éxito exportable que, al menos, evidencia lo universal de su temática, y que cuenta con una réplica en femenino La Cavernícola -Defending the Cavewoman- (Emma Peirson, 2000). Un fenómeno similar se produjo con la publicación de la novela del terapeuta John Gray (1993), Men Are from Mars, Women Are from Venus, betseller mundial devenido en un millonario negocio que analiza desde la ironía las relaciones de parejas heterosexuales, con el fin de mejorarlas. En el mismo sentido, se desarrolla una parte de la filmografía de Woody Allen o, las tiras cómicas de las Mujeres Alteradas de Maitena. Esta reiteración sería coherente con los hallazgos alcanzados por Izquierdo y Barbeta (2013: 1107) en un análisis reciente sobre chistes convencionales.

De los 56 memes clasificados en la categoría 'Mujeres y Hombres', dos terceras partes están vinculadas a representaciones sexistas (tabla 2). Las mujeres han sido tradicionalmente blanco de bromas machistas, adjudicándolas atributos muy diversos que proyectan un particular estereotipo de 'la feminidad': cotillas, marujas, consumistas, normativas, aprovechadas, frías sexuales o calculadoras. Por su parte, los estereotipos de la masculinidad hegemónica-sexismo convencional- adjudica a los varones múltiples caracteres desvalorizantes: promiscuos, desconsiderados, no comunicativos, crédulos, inconscientes, no románticos, obsesos futboleros, etc.

26 Website comercial de la obra original Defending the Caveman -http://defendingthecaveman.com/about-the-show/-, fecha de acceso febrero de 2016 
Tabla 2: Sub-categorías dentro de la categoría 'Mujeres y Hombres'.

\begin{tabular}{|c|c|c|}
\hline Sub-categorías & $\begin{array}{l}\text { Recuento } \\
\text { absoluto }\end{array}$ & Porcentaje \\
\hline Convivencia y conflicto & 6 & 10,7 \\
\hline Representaciones sexistas & 38 & 67,9 \\
\hline $\begin{array}{ll}\bullet & \text { Sexismo convencional } \\
\bullet & \text { 'Síndrome de la mujer-mujer' }\end{array}$ & $\begin{array}{l}(32) \\
(06)\end{array}$ & \\
\hline Ligar 'misión imposible' & 7 & 12,5 \\
\hline Advertencias & 3 & 5,4 \\
\hline Otros & 2 & 3,6 \\
\hline TOTAL & 56 & 100,0 \\
\hline
\end{tabular}

Esta observación de 'imaginarios virtuales', a partir de memes distribuidos, advierte que las representaciones convencionales, tan simplificadoras de la diversidad que somos, lejos de extinguirse siguen activas (Kotthoff, 2006; Bing, 2007; Shifman y Lemish, 2010). O incluso, se intensifican más si cabe, con la propuesta de memes que toma a los varones que participan del trabajo doméstico y de cuidados como objeto de guasa y que, en esta reflexión, se ha querido denominar con el término 'síndrome de la mujer-mujer' (tabla 2). Este 'trastorno' se manifestaría en la auto-percepción de superioridad de muchas mujeres en la gestión de las tareas de hogar y, por el cual, en paralelo a las prácticas de elusión ordinaria de los varones en el trabajo doméstico, se sustrae a los hombres la capacidad de asumir faenas para satisfacer las necesidades de la vida cotidiana -cocinar, planchar o cuidar a las criaturas- (cuadro 6). Una temática ya sugerida por la narrativa fílmica en clave de comedia, por la directora Coline Serreau en la película Trois hommes et un couffin (1985) ${ }^{27}$.

${ }^{27}$ El éxito comercial de la comedia francesa propició, qué novedad, una versión americana dos años después en Three Men and a Baby (1987). 
Cuadro 6: Memes que proyectan el 'síndorme de la mujer-mujer'.
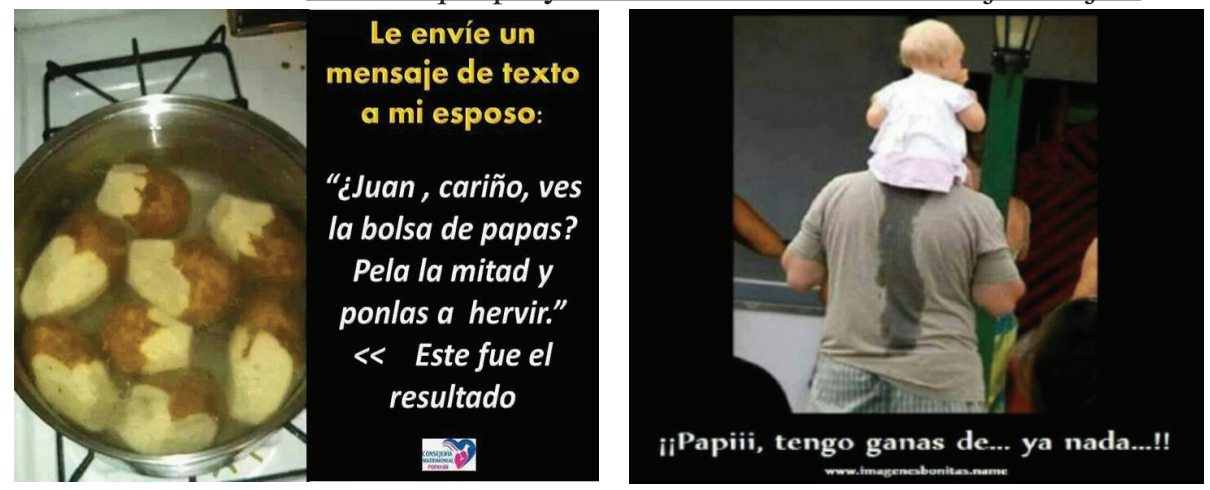

E1 humor operaría como un mecanismo social para reírse de los desencuentros de cada día, acumulados y sedimentados en las relaciones de pareja. Mediante la ridiculización y la exageración se invierten los dispositivos de tensión y conflicto y, mediante el divertimento, se expresan los 'sinsabores' de las asimetrías, en este caso de género. Esta actitud sugiere que todos los hombres, con independencia de sus prácticas, son torpes, lo que implica un exceso sexista (Izquierdo y Barbeta, 2013: 1121). El 'síndrome de la mujermujer' operaría, en última instancia, como reafirmación y reproducción del papel subalterno que nos adjudicó la división sexual del trabajo. Cuando las mujeres nos reímos de la torpeza de los varones, estamos expresando una omnipotencia patológica del 'expertise' de lo doméstico y, por tanto, estamos inconscientemente anclándonos al hogar como dominio; produciendo un efecto 'boomerang', aunque seguramente indeseado. Un proceso que recuerda la etnografía de Paul Willis -Learning to Labor, 1977-; algunas formas de resistencia acaban por reforzar lo que se trata de eludir. De forma que ciertas representaciones 'convencionales' de la feminidad y la masculinidad hegemónicas siguen ancladas a nuestro fluido cultural (Shifman y Lemish, 2010: 3-4).

Se revela así un marco de ambivalencia del humor, capaz de trascender al debate político. ¿Representar desde lo cómico los malestares cotidianos, demoscópicamente tabulados, es una forma de visibilizar o perpetuar la desigualdad?28. Por un lado, los memes arrancan, por identificación, una sonrisa fácil que, en opinión de algunas autoras, implica restar gravedad a la discriminación (Ortíz Gómez y Arco Bravo, 2012: 282). No obstante, relativizar mediante la risa las tensiones y malestares podría también interpretarse como la

${ }^{28}$ Los datos disponibles en la última Encuesta de Empleo del Tiempo (2011) señalan que las mujeres dedican, en promedio, cada día dos horas y cuarto más que los hombres a las tareas del hogar.

EMPIRIA. Revista de Metodología de Ciencias Sociales. N. ${ }^{o}$ 35, septiembre - diciembre, 2016, pp. 21-45. ISSN: 1139-5737, DOI/ empiria.35.2016.17167 
necesidad de mi derecho al sainete. Una situación que reflejaría las controversias y contradicciones de las que todas y todos somos portadores (Martín Criado, 2014). Consideremos un último ejemplo, la película Ocho apellidos vascos (2014) obtuvo críticas dispares. Se la reprocha ser una correa de distribución de estereotipos y, sin embargo, debe analizarse como un fenómeno sociológico, por haberse convertido en record de recaudación. La gente fue masivamente al cine y se rio de temas que, habiendo generado malestares históricos, podían ser leídos como 'disparate cómico' mediante el juego de tópicos entre población andaluza $\mathrm{y} \mathrm{vasca}^{29}$. ¿Es necesario poner límites al humor? O, por su propia naturaleza, ¿el humor no puede tornarse en serio?

\subsection{Expresando el deseo}

El dominio del orden patriarcal ha transmitido durante siglos una educación socio-cultural que adscribe a las mujeres una femineidad de la mesura que negaba, refrenaba o reprimía sus deseos sexuales. Esta cuestión se intensificaría con el paso de los años, llegando a construir el mito de que a edades avanzadas, la agencia erótica desaparece, o así se espera socialmente (Freixas y Luque, 2009: 192).

En la categoría denominada 'Expresando el deseo' se capturaron 33 memes, en los que se advierten evidencias de desinhibición en el consumo de alcohol o el placer sexual, tanto en versión interactiva como en versión auto-erótica (tabla 3). Las piezas compartidas se anclan a un dominio de la heterosexualidad, con una total ausencia de contenidos de orientación lésbica, bisexual o transexual.

Tabla 3: Sub-categorías dentro de la categoría 'Expresando el deseo'.

\begin{tabular}{lcr}
\hline \multicolumn{1}{c}{ Sub-categorías } & $\begin{array}{c}\text { Recuento } \\
\text { absoluto }\end{array}$ & Porcentaje \\
\hline Sustancias estimulantes & 11 & 33,3 \\
Sexo y placer & 22 & 66,6 \\
TOTAL & $\mathbf{3 3}$ & $\mathbf{1 0 0}$ \\
\hline
\end{tabular}

En esta temática es donde mejor se advierten giros de cambio social, promovidos por los movimientos feministas, y que estarían favoreciendo un principio de desinhibición desde una perspectiva humorística (Shifman y Lemish, 2010; Izquierdo y Barbeta, 2013: 1111). No obstante, el 'desmelene'

29 Un caso similar ocurrió con El diario de Bridget Jones (2001) que se convirtió en un éxito mundial pese a las furibudas críticas feministas que recibió (Martín, 2005: 90). 
plantea ciertas analogías con las producciones androcéntricas tradicionales. Por un lado, se compartieron memes de cuerpos masculinos semi-desnudos, como pícaras recreaciones visuales. Esta práctica, aparentemente liberadora, se interpreta aquí como una continuidad de las preferencias de la masculinidad tradicional, que exhibían cartelería erótica femenina en muchos espacios de trabajo -talleres- y en las habitaciones pobladas sólo por varones ${ }^{30}$. Además, en los últimos años se ha convertido en tendencia la comercialización de calendarios eróticos para mujeres, diseñados para recaudar fondos con fines sociales ${ }^{31}$ y que proponen ¿igualar? los gustos escópicos entre los géneros.

Más 'transgresora' resulta la promoción de juguetes eróticos denominados, por las compartidoras, 'manolitos', como referencias explícitas al derecho al autoerotismo y que supone indicar e intercambiar necesidades y emociones, largamente silenciadas (Freixas y Luque, 2009: 200). Muchos de estos memes ponen de manifiesto la centralidad del placer sexual en la vida de las mujeres, rompiendo la lógica del disimulo (Izquierdo y Barbeta, 2013: 1111).

Cuadro 7: Memes que proyectan una desinhibición del 'deseo'.

TODOS LOS HOMBRES BUSCAN SEXO EXCEPTO ENRIQUE IGLESIAS... Él SÓLO QUIERE ESTAR CONTIGO VIVIR CONTIGO Y BALLAR CONTIGO UNA NOCHE LOCA..

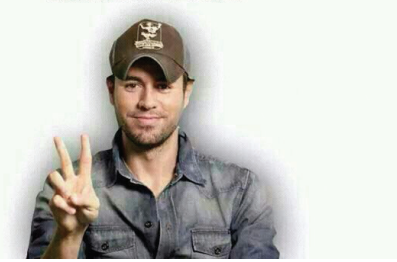

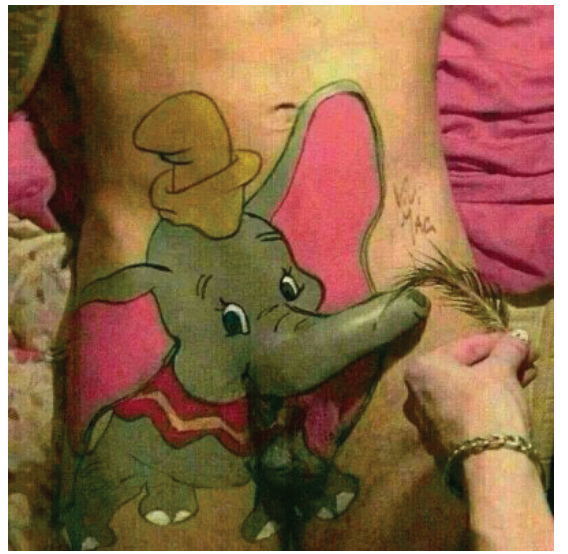

\subsection{La ambivalente relación con el cuerpo}

Durante siglos, el cuerpo femenino ha sido objetualizado y representado como espectáculo para el deleite de la mirada masculina (Berger, 1972: 5374 y Mayayo, 2003: 186-187). Es por ello que las mujeres han sido educadas

${ }^{30}$ En este sentido, resulta muy ilustrativo recordar el registro publicado por Berger y Mohr -A Seventh Man- (1975: 238) que describía el empapelado en las «Paredes de las habitaciones de obreros emigrantes en Suiza»

31 La película británica Calendar Girls (2003) -Las chicas del Calendario-, narraba la historia real de un grupo de mujeres que se fotografiaron desnudas en beneficio de la lucha contra la leucemia. 
para dejarse mirar, mirarse a sí mismas y a 'las otras', condicionadas a mostrar una correcta imagen que opera, paradójicamente, como violencia simbólica. De modo que, a diferencia de otros sujetos, el cuerpo de las mujeres no es un espacio propio, pues muchos discursos orientan cómo debe vestirse, maquillarse o en qué peso debe mantenerse, para ser atractivo.

Esta cuestión está presente en el corpus de memes capturado y clasificado en la categoría 'La ambivalente relación con el cuerpo' (tabla 4). La cultura de la belleza promocionada por los mensajes publicitarios ensalza la delgadez y el cuerpo escultural que se consigue y/o mantiene pasando hambre, con dietasmilagro, consumiendo productos de belleza o, simplemente, haciendo muchas horas de gimnasio.

Tabla 4: $\underline{\text { Sub-categorías dentro de la categoría 'La ambivalente relación con }}$ el cuerpo'.

\begin{tabular}{lcc}
\hline Sub-categorías & Recuento & Porcentaje \\
\hline Peso & 16 & 80,0 \\
Amenazas -calzado, sujetador, envejecimiento- & 4 & 20,0 \\
TOTAL & $\mathbf{2 0}$ & $\mathbf{1 0 0 , 0}$ \\
\hline
\end{tabular}

Frente a las campañas consumistas que pretenden que las mujeres maduras adquieran el síndrome de 'la falsa joven', las mujeres 'reales' se ríen de su ambivalente relación con el cuerpo. Los memes distribuidos indican la vigencia de la obsesión femenina por el control del peso ${ }^{32}$, mostrando una tensión irónica entre el 'ideal' estético y el placer del 'pincho' con cerveza. La variabilidad de peso tiene varios 'chivatos': la báscula y el tallaje de la ropa. La ropa estrecha es el indicio de que se han cruzado las líneas rojas y que es hora de iniciar una dieta. Por su parte, la relación con la báscula se convierte en un acto íntimo y, a la vez universal, entre una amplia base de mujeres.

Particularmente interesante resulta la distopía que proyecta el meme 'Barbie 50 aniversario' (cuadro 8). Un extraordinario ejemplo de hibridación de discursos, ligados desde la ironía y que proponen una re-significación en formato digital.

32 A este respecto conviene señalar que, los resultados de la Encuesta Nacional de Salud (2011-2012) informan que el sobrepeso y la obesidad afectan mucho más a los varones que a las mujeres y, sin embargo, son ellas las que soportan de manera incesante un discurso normativodisciplinario para vigilar y mantener en términos estéticos, que no saludables, su índice de masa corporal 
Cuadro 8: Re-significación, en formato meme, del 50 aniversario de Barbie Doll.

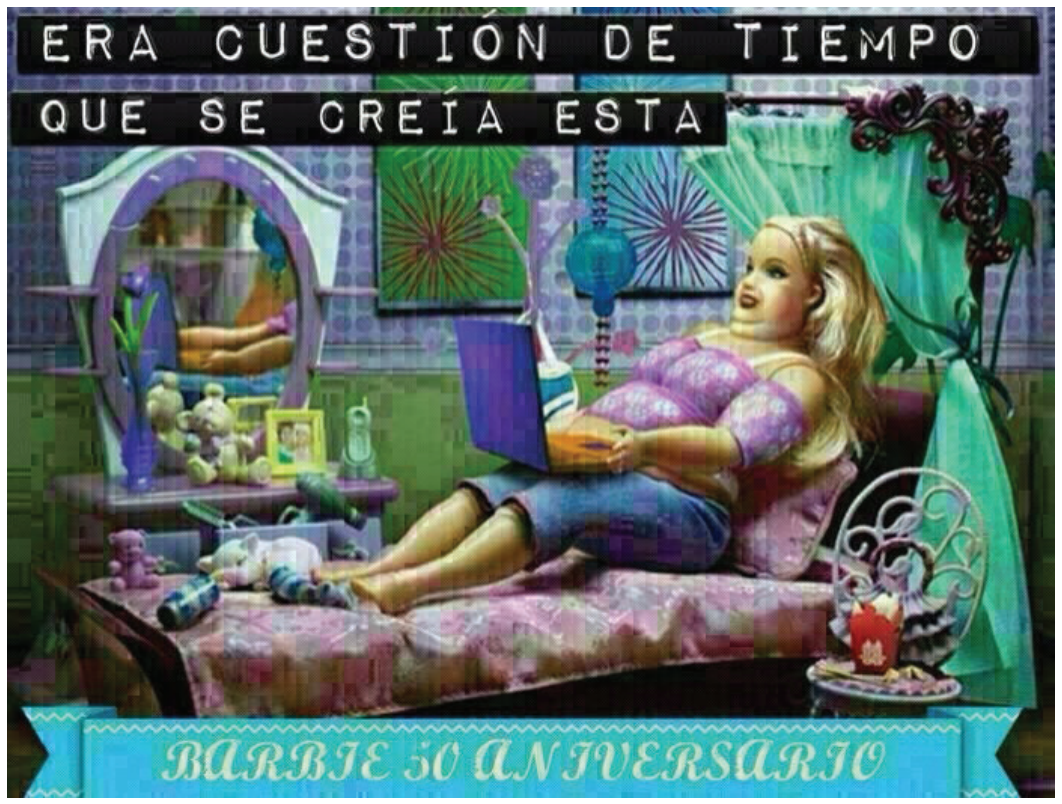

La ilustración que sirve de base al meme fue creada en 2009 por la agencia LatinWorks, por encargo de la organización Active Life Movement, con objeto de sensibilizar a la población estadounidense sobre los riesgos del sobrepeso infantil -Keep obesity away from your child ${ }^{33}$. Ese mismo año, Mattel celebraba el cincuenta aniversario de la muñeca diseñada por Ruth Moskowicz que encarnaba una artificiosa imagen de independencia femenina (Carreón, 2013: 68). La imagen muestra el desmoronamiento del mito de la eterna juventud proyectado por la controvertida muñeca-juguete que durante cinco décadas ha promovido con éxito, a juzgar por las estadísticas de ventas ${ }^{34}$, una idealización extrema del cuerpo femenino.

Probablemente, los creativos del cartel no repararon que la desfiguración del prototipo serviría para reafirmar un discurso crítico de resistencia. En las manifestaciones del 8 de marzo es habitual corear el eslogan: Abajo las barbies Arriba las barriguitas ${ }^{35}$, un contenido de reivindicación presente en

${ }^{33}$ La campaña publicitaria constaba de tres piezas en las que aparecían Superman, Barbie y piratas Playmobil desfigurados por abusar de la comida basura y la vida sedentaria.

${ }^{34}$ Baste una referencia, sólo en el año 2009, según The Telegraph, esta muñeca de 30 centímetros de altura reportó a Mattel, en el año 2009, 3.300 millones de dólares http://www.telegraph. co.uk/news/worldnews/northamerica/usa/4014779/Doll-power-Barbie-celebrates-50th-anniversary-and-toy-world-dominance.html

${ }^{35}$ Grito que también ha sido plasmado en grafitis: JJ Merelo (Flickr): "Pintada cerca de Informática/Bellas Artes" (Parque Almunia, Granada), subida el 11 de marzo de 2005; Brocco 
otras campañas de alter-femineidad ${ }^{36}$. El anclaje lingüístico del meme resuelve la frustración de perseguir un imposible - mantenerse en una infra-talla-, pero también expresa con regocijo la conquista de venganza: «¡Era cuestión de tiempo...Qué se creía esta!». Una frase que desvela de forma sutil las supuestas envidias entre las distintas formas de ser mujer. De hecho, el término 'barbie' se emplea a menudo como adjetivo despectivo para referirse a las 'tontas guapas' que conquistan varones atractivos y/o adinerados.

No obstante, la imagen se presta a un análisis semiótico que permite advertir la vigencia de las inscripciones androcéntricas en la representación de las mujeres. Se presume que la muñeca está en su habitación, el espacio más privado del hogar y, por tanto, ubicada en el ámbito de la domesticidad. Barbie está tumbada en una cama, ennoblecida por el dosel, simulando una particular exhibición de la 'venus' que ya no es. La postura del cuerpo en decúbito supino es la disposición generalizada del desnudo en la pintura europea y que, según Berger, ha favorecido una 'forma de ver' a las mujeres como visiones- espectáculo (1972: 55). El paso del tiempo, el presente info-tecnológico, la mantiene ensimismada con su ordenador personal y al alcance del teléfono portátil que, en esta representación, devuelven el discurso conservador del aislamiento nomofóbico que producen las nuevas tecnologías, frente a interpretaciones más liberadoras-creativas sobre las potencialidades de la sociedad en red (Sádaba y Gordo, 2008; Lasén, 2012; Shifman, 2013). La decoración infantil del espacio -abundancia de peluches-, con toques de lujo (dosel), integra elementos de subordinación de la mujer a su imagen como son el espejo, el secador de pelo, o la pera de boxeo, asociada al entrenamiento personal. Este es un buen ejemplo de memética, es decir, de los procesos de resignificación, creatividad y expansión en los que se desarrollan la cultura digital y el humor.

\section{HIPÓTESIS INTERPRETATIVAS}

WhatsApp está favoreciendo nuevas formas de comunicación y vinculaciones sociales que han dejado de ser patrimonio exclusivo de las generaciones jóvenes. En estas páginas se ha explorado como la expansión y hegemonía de esta app de mensajería instantánea multimedia alberga algo más que el intercambio de mensajes. Esta plataforma, entre otras cosas, está transformando la experiencia cotidiana del humor al producir un singular producto cultural digital, los memes. Estas piezas proliferan y circulan de forma incesante en nuestros conversatorios y han hecho aumentar nuestra relación con la ironía, la sátira y la burla. En general, no llamamos a nadie para

(Flickr): "Abajo las barbis y arriba las barriguitas, hombre por dio" (Granada), subida el 12 de mayo de 2007.

${ }^{36}$ Ver, por ejemplo, la campaña de The Body Shop (1998) "There are 3 billion women who don't look like supermodels and only 8 who do". 
contarle un chiste, pero enviamos memes de manera frecuente, manteniendo y/o reforzando vínculos. De manera que, estas aplicaciones estarían enriqueciendo e inaugurando nuevas relaciones de intercambio, basadas en el humor.

Si bien, este artículo se apoya en el análisis de un único grupo (durante un tiempo limitado y orientando la observación a una línea de investigación -119 memes de los 491 capturados), los hallazgos sugeridos son coherentes con los resultados de otras investigaciones sobre humor y género, desarrolladas con técnicas tradicionales (Izquierdo y Barbeta, 2013) y emergentes (Shifman, 2012 y 2013). La expansión y hegemonía del WhatsApp, como un 'espacio intermedio' de interacción social se nos ha revelado como un interesante objeto de análisis.

La gramática empleada en los memes compartidos en WhatsApp, condensa y combina elementos audiovisuales que lo hacen diferente y distinto al chiste convencional. Aunque mantiene similitudes con la clásica viñeta de humor de la prensa gráfica en su composición, se enriquece y diversifica mediante la memética, es decir, atendiendo a la libre apropiación y re-significación de contenidos.

Muchos autores enfatizan a menudo que, en la sociedad info-tecnológica las posibilidades de crear contenidos se han democratizado, asimilando las potencialidades de las nuevas tecnologías de la información y la comunicación con las prácticas de las personas usuarias. En este sentido, sería necesario matizar estas afirmaciones generalistas y tratar de identificar los perfiles de las personas, efectivamente creadoras de contenidos. En el transcurso de esta observación virtual se pudo comprobar que las participantes no crearon ningún meme, constatado un predominio absoluto de la distribución, es decir, la ausencia del rol 'productor' en cuanto a memes de carácter humorístico se refiere.

Los resultados del análisis empírico sugieren que el humor compartido por un grupo de mujeres maduras y económicamente independientes no está exento de controversia, si se interpreta desde una perspectiva de género. Por un lado, los contenidos distribuidos presentan continuidades con las burlas habituales de feminidad y masculinidad hegemónicas. Los memes mantienen un tono sexista en las caracterizaciones estereotipadas de 'ellas' y 'ellos', así como de sus relaciones interpersonales como parejas heterosexuales. Es más, el sexismo se reafirma al convertir a los varones en blanco de bromas sexistas -síndrome de la mujer mujer-. La lentitud con la que se integra la cultura de la corresponsabilidad en las unidades de convivencia es ficcionada irónicamente con la caricatura de varones torpes frente al trabajo doméstico y de cuidados.

Por otro lado, se advierten algunas discontinuidades rupturistas en la asunción de roles tradicionales. El estatus de mesura de la feminidad se agrieta al admitir abiertamente el deseo sexual y el derecho al consumo de alcohol. Expresiones de actitud que se interpretan, aquí, como una materialización del cambio social del que han sido protagonistas las mujeres en las últimas décadas. Por lo que la hipótesis inicial de que las características socio-demográficas del grupo podían operar como un filtro para proyectar una distribución de memes 
distante de convencionalismos sociales sexuados, se debe desestimar sólo en parte.

La reflexión sugiere, en última instancia, que el humor es algo más que divertimento. Los memes anclados, en su producción y distribución, a un contexto socio-cultural concreto muestran evidencias del imaginario compartido, cómo nos vemos y nos ven, de qué nos reímos y cuándo somos objeto de risa. Algunas piezas, orientadas a aumentar y reforzar tópicos o, desfigurar identidades, invitan a preguntar si en el humor 'todo vale'. Muchos estímulos cómicos, lejos de la neutralidad, inducen a una interpretación tendenciosa que nos señalan que la risa también está mediada por la estructura social y, por tanto, está atravesada por el poder. Estos hallazgos, por tanto, descubren un interés sociológico por explorar y analizar estos nuevos espacios intermedios de comunicación, mediados por las nuevas tecnologías. Las aplicaciones de mensajería instantánea multimedia o, los memes como producto sociocultural no pueden ser vistos exclusivamente como experiencias lúdicas emergentes. Antes bien, se revelan como entornos de socialización que, de manera inconsciente, moldean actitudes y opiniones... aunque indicarlo implique 'aguar' la fiesta.

\section{BIBLIOGRAFÍA}

ABRIL, Gonzalo (2010): "Cultura visual y espacio público-político", Revista CIC -Cuadernos de Información y Comunicación-, núm. 15, pp. 21-36.

AIMC (2015): Navegantes en la red. Encuesta a usuarios de internet ( $17^{\circ}$ edición).

ALADRO, Eva (2005): "El Humor como medio cognitivo", Revista CIC -Cuadernos de Información y Comunicación-, núm. 9, pp. 317-327.

BALLESTEROS, Esmeralda (2016): "Barreras de acceso a las mujeres en el empleo ferroviario", Revista del Ministerio de Trabajo y Seguridad Social, no 121, serie Economía y Sociología.

BECKER, Howard (2007): Telling About Society, traducido como Para hablar de la sociedad: La Sociología no basta, Buenos Aires, Siglo XXI, 2015.

BENEITO, Roser (2015): Gente mayor y medios de comunicación sociales: rompiendo con la e-marginalidad-resultados preliminares- Universitat Oberta de Catalunya (UOC), disponible en línea http://www.uoc.edu/portal/es/uoc-news/ actualitat/2015/072-gente-grande-tic.html, fecha de acceso febrero de 2016.

BERGER, John (1972): Ways of seeing, Peguen Books Ltd., London, traducido como Modos de Ver, Barcelona, Gustavo Gili, séptima edición, 2002.

BERGER, John y MOHR, Jean (1975): A Seventh Man. A book of images and words about the experience of Migrant Workers in Europe, London, Writers and Readers Publishing Cooperative, 1982.

BERGER, Peter (1997): Risa redentora. La dimensión cómica de la experiencia humana, Barcelona, Kairós, 1999.

BING, Janet (2007): "Liberated jokes: Sexual humor in all-female groups", Humor, Vol. 20, núm. 4, págs. 337-366. 
BLAIS, Julie; CRAIG, Wendy; PEPLER, Debra; CONNOLLY, Jennifer (2008): "Adolescents Online: The Importance of Internet Activity Choices to Salient Relationships", Journal of Youth and Adolescence, Vol. 37, Issue 5, págs. 522-536.

BREA, José L. (2010): Las tres eras de la imagen. Imagen-materia, film, e-image, Madrid, Akal.

CARREÓN, Emilie (2013): "Barbie en Palenque, o la manufactura de lo intangible", Anales del Instituto de Investigaciones Estéticas, Vol. XXXV, número 102, págs. 65-91.

DYNEL, Marta (2016): “I has seen Image Macros!” Advice Animals memes as visualverbal jokes”, International Journal of Communication, núm. 10, págs. 660-688.

FREIXAS, Anna y LUQUE, Bárbara (2009): "El secreto mejor guardado: la sexualidad de las mujeres mayores", Política y Sociedad, Vol. 46, núm. 1 y 2, págs. 191-203.

GORDO, Ángel y MEGIAS, Ignacio (2006): Jóvenes y cultura Messenger, Madrid, Fundación de Ayuda contra la Drogadicción.

ISLAS CARMONA, Octavio (2008): "El prosumidor. El actor comunicativo de la sociedad de la ubicuidad", Palabra Clave, Vol. 11, núm. 1, págs. 29-39.

IZQUIERDO, Ma Jesús y BARBETA, Marc (2013): "La transcendencia de lo cotidiano: vínculos, chistes y subjetividad”, Política y sociedad, Vol. 50, núm. 3, págs. 10971131.

IZQUIERDO, Ma Jesús y BARBETA, Marc (2014): "Notas metodológicas sobre el análisis de los vínculos grupales mediante la identificación de las asociaciones de sentido en los chistes", EMPIRIA -Revista de Metodología de Ciencias Sociales-, núm. 33, págs. 139-171.

KOTTHOFF, Helga (2006): "Gender and Humor: The State of the Art", Journal of Pragmatics, vol. 38, no. 1, pp. 4-25.

LASÉN, Amparo (2012): “Autofotos. Subjetividades y Medios Sociales", en GarcíaCanclini, N. Cruces, F. y Guadarrama, M. (Ed.), Jóvenes, culturas urbanas y redes digitales. Prácticas emergentes en las artes, el campo editorial y la música, Madrid, Ariel, págs. 243-262.

LASÉN, Amparo y Elena CASADO (eds.) (2014): Mediaciones Tecnológicas. Cuerpos, afectos y subjetividades, Madrid, CIS-Universidad Complutense de Madrid.

MARTÍN ALEGRE, Sara (2005): "El miedo a la risa: un debate en torno a Bridget Jones, heroína de Helen Fielding”, Dossiers feministes, núm. 8, págs. 89-102.

MARTÍN CRIADO, Enrique (2014): "Mentiras, inconsistencias y ambivalencias. Teoría de la acción y análisis de discurso", Revista Internacional de Sociología, Vol. 72, núm. 1, págs. 115-138.

MARTIN, Phiona y BARNARD, Antoni (2013): "The experience of women in maledominated occupations: A constructivist grounded theory inquiry", SA Journal of Industrial Psychology, Vol. 39, núm. 2, disponible en línea http://www.sajip.co.za/ index.php/sajip/article/viewFile/1099/1323, fecha de acceso junio de 2014.

MENET, Jonathan (2016): "YOMONI, un acteur de l'épargne à la mode du MEME", disponible en http://www.jonathan-menet.fr/blog/2016/01/19/yomoni-un-acteur-delepargne-a-la-mode-du-meme/, fecha de acceso febrero de 2016.

ORTIZ GÓMEZ, María Jesús y Miguel Ángel DEL ARCO BRAVO (2012): "Dieciocho años del Observatorio de la Imagen de las Mujeres", Cuestiones de género: de la igualdad y la diferencia, núm. 7, págs. 269-295.

ROMERO, Juana y PERLADO, Marta (2015): “El fenómeno WhatsApp en el contexto de la comunicación personal: una aproximación a través de los jóvenes universitarios", Icono 14, Vol. 13, págs. 73-94. 
SHIFMAN, Limor y LEMISH, Dafna (2010): "Between Feminism and Fun(ny)mism: Analyzing Gender in Popular Internet Humor", Information, Communication \& Society, Vol. 13, Issue 6, págs. 870-891.

SHIFMAN, Limor (2012): "An anatomy of a YouTube meme", New Media \& Society, Vol. 14, núm. 2, págs. 187-203.

SHIFMAN, Limor (2013): Memes in Digital Culture, MIT Press.

SEGADO BOJ, Francisco (2009): "Un tópico perpetuado. La imagen de la mujer y el feminismo en el humor gráfico de la prensa diaria durante la transición (19741977)", Zer -Revista de estudios de comunicación-, núm. 27, págs. 203-224.

STATISTA (2016): Mobile messenger apps - Statista Dossier-, Statista, Inc. (NY)

URROZ, Teresa (2005): "Cómo reírse de una misma y no morir en el intento", Dossiers Feministes, núm. 8, págs. 7-14.

VIGARA TAUSTE, Ana Ma (1994): El chiste y la comunicación lúdica: lenguaje y praxis, capítulo 1, Madrid, Ediciones Libertarias, reproducido en Espéculo (2013), núm. 50, -Revista de estudios literarios UCM- , págs. 8-27.

WESCH, Michael (2009): "YouTube and You: Experiences of Self-awareness in the Context Collapse of the Recording Webcam", Explorations in Media Ecology, Vol. 8 (2), págs. 19-34.

WIGGINS, Bradley y BOWERS, Bret (2015): "Memes as genre: A structurational analysis of the memescape", New Media \& Society, Vol. 17, núm. 11, págs. 18861906. 
